\title{
Palivizumab in the prevention of severe respiratory syncytial virus infection in children with congenital heart disease; a novel cost-utility modeling study reflecting evidence-based clinical pathways in Spain
}

\author{
Ralph Schmidt ${ }^{*}$ (D), Istvan Majer ${ }^{2}$, Natalia García Román ${ }^{3}$, Alejandra Rivas Basterra ${ }^{4}$, ElizaBeth Grubb ${ }^{5}$ \\ and Constancio Medrano López ${ }^{6}$
}

\begin{abstract}
Background: Respiratory syncytial virus (RSV) infection remains one of the major reasons of re-hospitalization among children with congenital heart disease (CHD). This study estimated the cost-effectiveness of palivizumab prophylaxis versus placebo, in Spain, from the societal perspective, using a novel cost-effectiveness model reflecting evidence-based clinical pathways.

Methods: A decision-analytic model, combining a decision tree structure in the first year and a Markov structure in later years, was constructed to evaluate the benefits and costs associated with palivizumab versus no prophylaxis among children with CHD. In the first year of the model, children were at risk of mild (i.e. medically attended, MARSV) and severe (hospitalized, RSV-H) RSV infection. The impact of delayed corrective CHD surgery due to RSV infection and the consequence of performed surgery despite severe infection were considered. In later years, patients were at risk of developing asthma and allergic sensitization as sequelae of RSV infection. Input data for the model were derived from the pivotal clinical trial and systematic literature reviews. Indirect costs included parental absence from work and nosocomial infections. In agreement with Spanish guidelines, costs and effects were discounted at 3\%.

Results: Over a lifetime horizon, palivizumab prophylaxis yielded 0.11 and 0.07 additional quality-adjusted life years (QALYS) and life years (LYS), respectively, at additional costs of $€ 1,693$, resulting in an ICER of $€ 15,748$ per QALY gained and $€ 24,936$ per LY gained. Probabilistic sensitivity analyses demonstrated that the probability of palivizumab prophylaxis being cost-effective at a $€ 30,000$ per QALY threshold was $92.7 \%$. The ICER remained below this threshold for most extreme scenario analyses.

Conclusions: The model demonstrated that palivizumab prophylaxis results in more QALYS than no prophylaxis in children with CHD. Palivizumab prophylaxis was shown to be a cost-effective health care intervention according to the commonly accepted standards of cost-effectiveness in Spain (ICER below the threshold of $€$ 30,000 per QALY).
\end{abstract}

Keywords: Palivizumab, Prophylaxis, Cost-effectiveness, Respiratory syncytial virus, Congenital heart disease, Spain

\footnotetext{
* Correspondence: rschmidt@pharmerit.com

${ }^{1}$ Pharmerit International, Health Economics and Outcomes Research,

Zimmerstraße 55, 10117 Berlin, Germany

Full list of author information is available at the end of the article
} 


\section{Background}

The human respiratory syncytial virus (RSV) is known to cause acute lower respiratory tract infections (LRTIs) during infancy and childhood. RSV activity can vary geographically, with the peak season for temperate climates lasting any time between November and April [1, 2]. Approximately, $60 \%$ of infants are infected during their first RSV season and almost all by the age of two [3]. In these infants, RSV infection may result in complications (e.g. bronchiolitis and acute respiratory or ventilatory failure) necessitating hospitalization and sometimes mechanical ventilation with transfer to an intensive care unit (ICU) [4]. Globally, 34 million episodes of acute LRTIs, 3.4 million hospitalizations and 199,000 deaths are estimated to occur due to RSV each year [3].

The clinical burden associated with RSV infection differs considerably between patients. In most cases, RSV infection presents itself as a common cold and requires no medical attention. However, in other cases, patients have serious negative health consequences that are known to result in respiratory problems that can last into adulthood. The economic burden of RSV has been estimated at an annual cost of $€ 47$ million for the Spanish National Health Care System [5].

In general, three subgroups of children are considered to be at increased risk of severe infection: children with congenital heart disease (CHD), children with chronic lung disease (CLD), and infants who are prematurely born (i.e. born prior to the 37th week of gestation). Within this latter group, children are further stratified by their gestational age and the presence of additional risk factors such as contact with other children and lack of breast feeding [6]. In the present cost-utility analysis, we focus on children with CHD.

Given the significant humanistic and economic burden of RSV infection in high risk groups [5-8], prevention of infection is highly recommended by the Spanish Association of Pediatrics (Asociación Española de Pediatría) $[9,10]$ as well the Spanish Society of Pediatric Cardiology and Congenital Heart Disease (Sociedad Española de Cerdiolohia Pediatrica y Cardiopatias Congenitas) [11]. To date, no RSV vaccine or antiviral therapy exists and the most effective method of prevention is prophylaxis with palivizumab [12]. Palivizumab is an FDA- and EMA-approved prescription injection of RSV-targeting antibodies and was granted access to most markets in the late 1990s [2]. During an RSV season, it is administered monthly via the intramuscular route, at a dose of $15 \mathrm{mg} / \mathrm{kg}$ [13].

The efficacy of palivizumab has been demonstrated in three randomized, double-blind, placebo-controlled clinical trials: the IMpact trial $(n=1502),[14]$ the MAKI trial $(n=429),[15]$ and the Feltes trial $(n=1287)$ [16]. The IMpact trial investigated the reduction in RSV- related hospitalizations among premature infants or children with CLD during the first RSV season of their life. Results from this trial showed that palivizumab prophylaxis was associated with a 55\% (95\% confidence interval [CI] 38-72\%) reduction in hospitalizations. The more recent MAKI trial focused on parent-reported wheezing patterns in late preterm infants who received palivizumab or placebo (no prophylaxis). The study demonstrated a $47 \%(95 \%$ CI $14-80 \%)$ reduction in the number of patients suffering from recurrent wheezing and proved that palivizumab treatment significantly reduced the need for RSV-related outpatient visits in mild cases of RSV infection. The Feltes study included children ( $\leq 2$ years of age) with CHD and demonstrated that palivizumab recipients had a $45 \%$ (95\% CI $23-67 \%)$ relative risk reduction (RRR) in RSV hospitalizations.

Previously, several health economic evaluations comparing palivizumab prophylaxis with placebo have been performed [17-25]. Among these, a handful of evaluations focused on children with CHD [24-27]. Although the evaluations differed in terms of the modeling approach, input data, model outcomes and the estimated results, none of the studies sufficiently captured the impact of the complicated disease course in children with CHD. Specifically, the risk of delayed and complicated heart surgery as a severe RSV-related complication was not incorporated. Additionally, previously published studies did not consider patients with MA-RSV, longterm respiratory sequelae of RSV infection (asthma and allergic sensitization), and the impact of hospitalacquired nosocomial infections. The present study assessed the cost-utility of prophylaxis with palivizumab versus no prophylaxis in children with CHD in Spain, using a health economic model that captured the complexities of the RSV disease course as well as the specific clinical pathway of CHD patients. The analysis was conducted from a societal perspective.

\section{Methods \\ Model structure}

A decision-analytic model was developed in Microsoft Excel 2016, combining a decision tree structure for the first year (see Fig. 1) and a Markov structure for subsequent years (annual cycles, please see Fig. 2). In line with the Feltes trial design, patients received either palivizumab or placebo (i.e. no prophylaxis) during their first RSV season (year 1).

Since most children with CHD require cardiac surgery to correct the heart defects early in life, the decision tree structure applied in the first year was deemed appropriate to capture potential complications in children scheduled for heart surgeries. Children could experience three possible events during this first year: no identified RSV infection ('No RSV' branch), medically attended RSV 


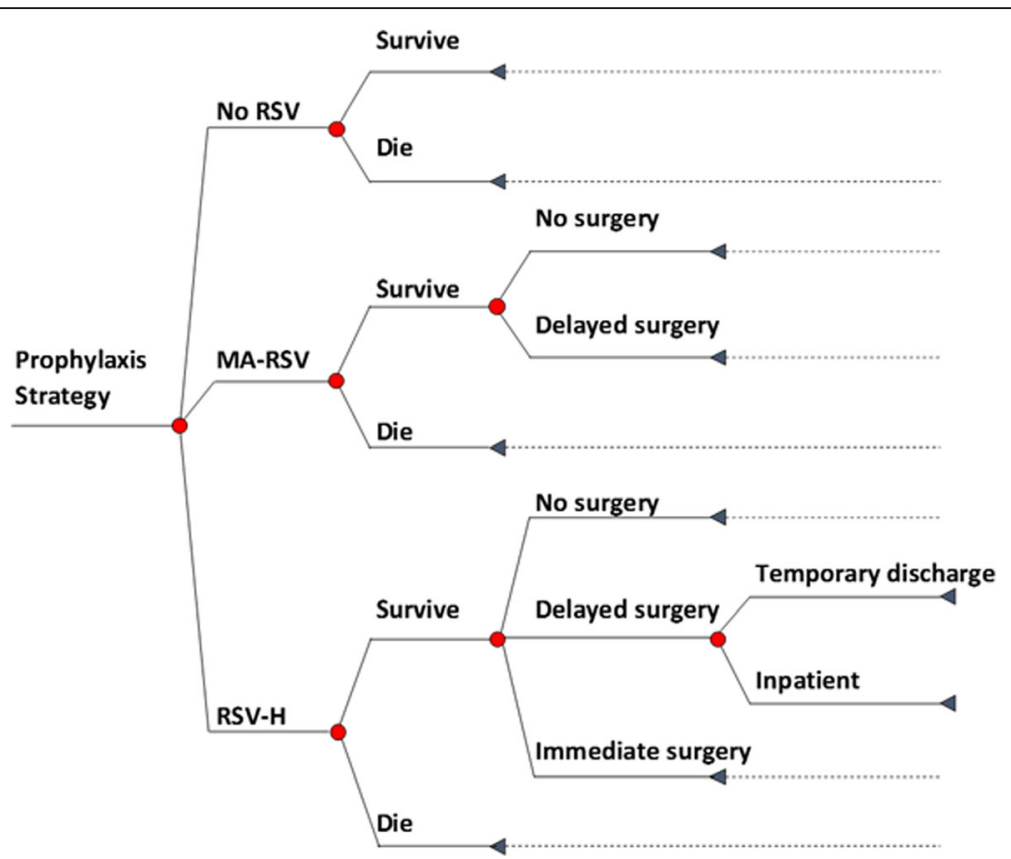

Fig. 1 Decision tree model structure for children with CHD during the first year of the model simulation. Abbreviations: RSV, respiratory syncytial virus; MA-RSV, medically attended RSV infection; RSV-H, RSV infection resulting in hospitalization

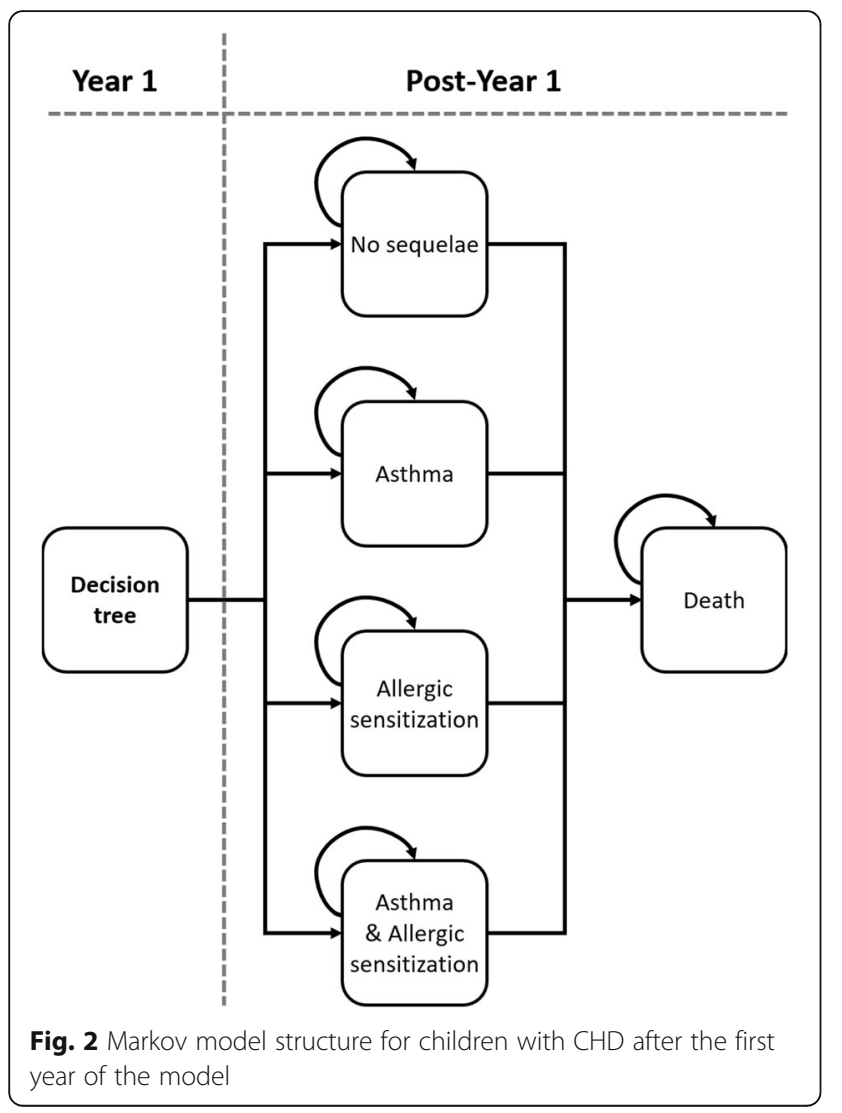

infection ('MA-RSV') or RSV hospitalization ('RSV-H'). Among those who were hospitalized for severe RSV infection, three possible events were further considered: 'No (planned) surgery' (due to either not requiring surgery at all or having had corrective surgery before the infection), 'Delayed surgery' (i.e. surgery postponed until after RSV infection is cleared), and 'Immediate surgery', with consequences of increased health care resource utilization. Regarding MA-RSV patients, immediate surgery was deemed not to be a clinically relevant outcome, because these patients, by definition, were not in the hospital at the time of the RSV infection and any scheduled surgery must have been further away in time. Therefore, RSV-related complications associated with immediate surgery did not need to be captured for the MA-RSV patients in the model.

After the first year of the simulation, patients entered the Markov model where their health status was evaluated annually (i.e. every model cycle) over a lifetime horizon (i.e. until the age of 100 years). It has been established that the health impact of RSV infection extends beyond the acute episode phase [28]. In particular, significant risk increases in developing asthma and allergy after RSV infection in the first year of life have been documented, even at the age of 18 years [29]. Therefore, the health states considered in the Markov model were directly related to the presence of long-term respiratory sequelae. Four mutually exclusive health states were distinguished: asthma, allergic sensitization, 
both asthma and allergic sensitization, and no long-term sequelae. Patients remained in these health states until 18 years of age or death. The modeling approach was validated by a pediatric cardiologist who is an expert in the disease field.

\section{Efficacy input parameters}

All efficacy input parameters are presented in Table 1, whereas the transition probabilities from the decision tree to the Markov model and related calculations are shown in Table 2. The risks of RSV-H and MA-RSV were based on the results of the pivotal trial of Feltes et al. [16] and the MAKI trial [15], respectively. The risks of immediate and delayed surgery were derived from a United States (US)-based retrospective study, that assessed hospital charts of children with a pre-RSV infection cardiac diagnosis [30]. Patients in this retrospective study were categorized as either surgical or medical. Surgical patients were children who underwent congenital heart surgery and had RSV infection during the same hospitalization. Medical patients were children with CHD who were hospitalized with RSV infection but did not undergo cardiac surgery during the admission for RSV. Medical patients were distinguished by delayed surgery and no surgery. In addition to this, patients with delayed surgery were further categorized into inpatient (i.e. requiring hospitalization until the surgery) and outpatient (i.e. discharged to home until the surgery) subgroups. The probabilities of patients arriving at each of the modeled branches were taken from this retrospective study [30], except for the inpatient and outpatient subgroups within patients with delayed surgery, for which input data was informed by clinical expert opinion.

The model made a distinction between two types of mortality, one that reflected the elevated mortality among children with CHD hospitalized for RSV, referred to as case fatality, and one that related to any other cause of death, referred to as background mortality. The case fatality rate was applied only in the first year of the simulation (i.e. in the decision tree) and was applied to RSV-H patients only, whereas the background mortality

Table 1 Efficacy input parameters

\begin{tabular}{|c|c|c|c|c|}
\hline Parameter & Palivizumab (SE) & No prophylaxis (SE) & Distribution in PSA & Source \\
\hline \multicolumn{5}{|l|}{ First year (decision tree) } \\
\hline MA-RSV risk, \% & $1.9(0.4)$ & $8.1(1.6)$ & Beta & $\begin{array}{l}\text { MAKI trial (2013, Feltes et al. } \\
\text { (2003) }\end{array}$ \\
\hline RSV-H risk, \% & $5.3(0.9)$ & $9.7(1.9)$ & Beta & Feltes et al. (2003) \\
\hline RSV-H: Immediate surgery, \% & $11.1(4.0)$ & $11.1(4.0)$ & Beta & Altman et al. (2000) \\
\hline RSV-H: No immediate surgery, \% & $88.9(17.8)$ & $88.9(17.8)$ & Beta & Altman et al. (2000) \\
\hline No surgery, \% & $39.3(7.9)$ & $39.3(7.9)$ & Beta & Altman et al. (2000) \\
\hline Delayed surgery, \% & $60.7(6.5)$ & $60.7(6.5)$ & Beta & Altman et al. (2000) \\
\hline $\begin{array}{l}\text { Inpatient vs discharged before } \\
\text { delayed surgery, } \%\end{array}$ & 33 vs $67(8.1)$ & 33 vs 67 (8.1) & Beta & Expert opinion* \\
\hline Case fatality, \% & $5.2(0.9)$ & $5.2(0.9)$ & Beta & Szabo et al. (2013) \\
\hline $\begin{array}{l}\text { CHD-specific background mortality } \\
\text { (first } 20 \text { years) }\end{array}$ & age-specific mortality & age-specific mortality & Fixed & Tennant et al. (2010) \\
\hline $\begin{array}{l}\text { CHD-specific background mortality } \\
\text { (beyond } 20 \text { years) }\end{array}$ & age-specific mortality & age-specific mortality & Fixed & $\begin{array}{l}\text { Diller et al. (2015), National } \\
\text { mortality statistics (Spain, 2012) }\end{array}$ \\
\hline \multicolumn{5}{|c|}{ Proportions of respiratory sequelae (used for transition probability calculations, see Table 2) } \\
\hline \multicolumn{5}{|l|}{ MA-RSV: } \\
\hline Asthma, \% & $10.3(1.1)$ & $10.3(1.1)$ & Beta & Stein et al. (1999) \\
\hline Allergic sensitization, \% & $37.4(3.9)$ & $37.4(3.9)$ & Beta & Sigurs et al. (2010) \\
\hline \multicolumn{5}{|l|}{ RSV-H: } \\
\hline Asthma, \% & $32.6(6.9)$ & $32.6(6.9)$ & Beta & Stein et al. (1999) \\
\hline Allergic sensitization, \% & $43.5(7.3)$ & $43.5(7.3)$ & Beta & Sigurs et al. (2010) \\
\hline \multicolumn{5}{|l|}{ Other parameter } \\
\hline Nosocomial infection, \% & $6.1(0.6)$ & $6.1(0.6)$ & Beta & Ehlken et al. (2005) \\
\hline
\end{tabular}

*The SE was assumed to be $20 \%$ of the estimated mean Abbreviations: SE, standard error; PSA, probabilistic sensitivity analysis; RSV, respiratory syncytial virus; MA-RSV, medically attended RSV infection; RSV-H, RSV infection resulting in hospitalization 
Table 2 Transition probabilities from the decision tree to the Markov model

\begin{tabular}{lll}
\hline Parameter & Transition probability (Palivizumab and no prophylaxis) & Calculation (see Table 1 for efficacy inputs) \\
\hline MA-RSV & 56.1 & $\left(1-p_{\text {Asthma }}\right) \times\left(1-p_{\text {AS }}\right)$ \\
No sequelae, \% & 6.4 & $p_{\text {Asthma }} \times\left(1-p_{\text {AS }}\right)$ \\
Asthma, \% & 33.6 & $\left(1-p_{\text {Asthma }}\right) \times p_{\text {AS }}$ \\
Allergic sensitization, \% & 3.9 & $p_{\text {Asthma }} \times p_{\text {AS }}$ \\
Asthma and allergic sensitization, \% & & \\
RSV-H & 38.1 & $\left(1-p_{\text {Asthma }}\right) \times\left(1-p_{\text {AS }}\right)$ \\
No sequelae, \% & 18.4 & $p_{\text {Asthma }} \times\left(1-p_{\text {AS }}\right)$ \\
Asthma, \% & 29.3 & $\left(1-p_{\text {Asthma }}\right) \times p_{\text {AS }}$ \\
Allergic sensitization, \% & 14.2 & $p_{\text {Asthma }} \times p_{\text {AS }}$ \\
Asthma and allergic sensitization, \% &
\end{tabular}

Abbreviations: RSV, respiratory syncytial virus; MA-RSV, medically attended RSV infection; AS, allergic sensitization; RSV-H, RSV infection resulting in hospitalization

was applied annually throughout the whole simulation to all patients. The case fatality risk was applied equally to both model arms, assuming no effect of prophylaxis on the risk of death for RSV-H children. It was derived from a meta-analysis study that included several articles reporting case fatality rates in young children with CHD hospitalized for severe RSV LRTI [31], and has been used in a previous modeling study [24]. The CHDspecific background mortality was sourced from two publications and was applied to all years of the simulation. For the first 20 years of the simulation, the model made use of mortality data published by Tennant et al. [32], who reported a 1-year survival of $92.3 \%$ and a 20 year survival of $89.5 \%$ in children with different types of congenital anomalies of the cardiovascular system. Based on these figures, the background mortality risk applied in the model was $7.7 \%$ for the first year and $0.16 \%$ for years 2-20 (risk of death over a 19-year period, i.e. 1$89.5 \% / 92.3 \%$, annualized). Beyond 20 years, the model was informed by age-specific general population mortality data from the national mortality statistics published for Spain (2012) [33] that was adjusted by the difference between the adult CHD population and the general population (standardized mortality ratio [SMR]: 2.29 as published in Diller et al. [34]).

MA-RSV and RSV-H have been identified as possible risk factors for asthma (or recurrent wheezing) and allergic sensitization in genetically predisposed children $[29,35,36]$. The distribution over the Markov health states, at the moment of transitioning from the first year (decision tree) to the second year, was informed by two studies, Sigurs et al. [29] and Stein et al. [36], that reported estimates of the association of RSV infection (severe and mild) and long-term respiratory sequelae. We used different incidence rates of respiratory sequelae for patients with MA-RSV and RSV-H. Patients without an MA-RSV or RSV-H infection were assumed to be free of RSV-induced respiratory illnesses. Probabilities of sequelae, along with their respective calculations, are outlined in Table 2. Based on the findings of the Sigurs et al. study [29], respiratory sequelae were assumed to last 18 years.

A novel aspect of the current model is the inclusion of nosocomial infections. The transmission risk, i.e., the risk that children with RSV-H can infect other hospitalized children was taken from a publication by Ehlken et al. which investigated the impact of nosocomial-acquired LRTIs in young children [37]. In the model, we assumed that whenever a nosocomial infection occurs, only one RSV-H patient transmits the infection to only one other child and the cost of such nosocomial infections were considered.

\section{Utilities}

Utility values for the different health states were derived from published literature and are presented in Table 3. Greenough et al. conducted a retrospective study on health-related quality of life (HRQoL) in prematurely born children in the United Kingdom (UK) [38]. The study compared the HRQoL of children with RSV-H and without RSV-H at the age of five years, using the Health Utilities Index (HUI) measure. The median HUI was 0.88 and 0.95 in the two groups of children, respectively. The mean scores were not reported. For the purpose of the model, it was assumed that the decrement of 0.070 was applicable for the first five model cycles (decision tree and four Markov cycles). The same utility values were used in previous cost-utility models $[17,21,24,39-41]$. After the age of five years, HRQoL was assumed to be impacted only by the presence of RSV-induced respiratory sequelae. The disutility for asthma (0.048) was obtained from a publication by Briggs et al. [42], who investigated the cost-effectiveness of asthma control in the UK, by using data from the Gaining Optimal Asthma Control (GOAL) study. The disutility of allergic sensitization (0.046) was reported in 
Table 3 Utility and cost parameters

\begin{tabular}{|c|c|c|c|}
\hline & Palivizumab/placebo (SE) & Distribution in PSA & Source \\
\hline \multicolumn{4}{|l|}{ Utilities } \\
\hline Baseline (age 0-17 years) & $0.950(0.162)$ & Beta & Greenough et al. (2004) \\
\hline Baseline (age 18-24 years) & $0.982(0.003)$ & Beta & Szende et al. (2014) \\
\hline Baseline (age 25-34 years) & $0.975(0.003)$ & Beta & Szende et al. (2014) \\
\hline Baseline (age 35-44 years) & $0.949(0.009)$ & Beta & Szende et al. (2014) \\
\hline Baseline (age $45-54$ years) & $0.923(0.010)$ & Beta & Szende et al. (2014) \\
\hline Baseline (age 55-64 years) & $0.901(0.009)$ & Beta & Szende et al. (2014) \\
\hline Baseline (age 65-74 years) & $0.891(0.007)$ & Beta & Szende et al. (2014) \\
\hline Baseline (age 75 years onwards) & $0.781(0.014)$ & Beta & Szende et al. (2014) \\
\hline Decrement: RSV-H & $0.070(0.014)$ & Beta & Greenough et al.(2004) \\
\hline Decrement: asthma & $0.048(0.010)$ & Lognormal & Briggs et al. (2006) \\
\hline Decrement: allergic sensitization & $0.046(0.009)$ & Lognormal & Brüggenjürgen et al. (2008) \\
\hline \multicolumn{4}{|l|}{ Direct costs } \\
\hline Prophylaxis cost & $€ 2902$ & Fixed & $\begin{array}{l}\text { Synagis vial cost, Pedraz et al. (2003), } \\
\text { Clinical expert input }\end{array}$ \\
\hline General ward hospital stay/day & $€ 591$ (€ 118) & Gamma & Lázaro y de Mercado et al. (2006) \\
\hline Intensive care support/day & $€ 1041(€ 208)$ & Gamma & Lázaro y de Mercado et al. (2006) \\
\hline Outpatient visit & $€ 21(€ 4)$ & Gamma & Dal Negro et al. (2007) \\
\hline Asthma/year & $€ 744$ (€ 149) & Gamma & Blasco Bravo et al. (2011) \\
\hline Allergy/year & $€ 198(€ 40)$ & Gamma & Smith et al. (2005) \\
\hline RSV-H (pediatric ward), days & $7(1.4)$ & Gamma & Medrano et al. (2010) \\
\hline RSV-H - ICU, days & $10(2.0)$ & Gamma & Medrano et al. (2010) \\
\hline Risk of ICU admission, \% & $30.4(6.1)$ & Beta & Medrano et al. (2010) \\
\hline Delayed surgery (outpatient), GP visits & $4(0.8)$ & Gamma & Expert opinion \\
\hline Delayed surgery (inpatient), days & $28(5.6)$ & Gamma & Expert opinion \\
\hline Immediate surgery, days & $\begin{array}{l}2.1(0.42) \text { length of stay } \\
\text { in pediatric ward }\end{array}$ & Gamma & Altman et al. (2000) \\
\hline \multicolumn{4}{|l|}{ Indirect costs } \\
\hline Missed work: Palivizumab administration, hours & $2(0.4)$ & Gamma & Assumption \\
\hline Missed work: MA-RSV, hours & $2(0.4)$ & Gamma & Assumption \\
\hline Missed work: RSV-H, hours & $57(11.5)$ & Gamma & Medrano et al. (2010), Assumption \\
\hline Asthma/year & $€ 495$ (€ 99) & Gamma & Blasco Bravo et al. (2011) \\
\hline Allergy/year & $€ 259(€ 52)$ & Gamma & Smith et al. (2005) \\
\hline Nosocomial infection: risk, \% & $6.1(0.6)$ & Beta & Ehlken et al. (2005) \\
\hline Nosocomial infection (pediatric ward), days & $14(2.8)$ & Gamma & Assumption, Expert opinion \\
\hline Absence from work/hour & $€ 20(€ 4)$ & Gamma & $\begin{array}{l}\text { Anuario Estadístico de Espana (2017; } \\
\text { Spanish statistical yearbook) }\end{array}$ \\
\hline
\end{tabular}

Notes: Presented costs were either 2016 costs or were inflated to 2016 costs

Abbreviations: GP, general practitioner, SE, standard error; PSA, probabilistic sensitivity analysis; RSV, respiratory syncytial virus; RSV-H, RSV infection resulting in hospitalization; ICU, intensive care unit; MA-RSV, medically attended RSV infection

a publication by Brüggenjürgen et al. [43], who evaluated the cost-effectiveness of specific subcutaneous immunotherapy in addition to symptomatic treatment compared with symptomatic treatment alone, in a German health care setting. These decrements in utility due to sequelae were assumed independent and (in the absence of further evidence) additive. Thus, a child who suffered from both asthma and allergic sensitization had an HRQoL loss of 0.094. Furthermore, in line with other publications $[24,40,41]$, the baseline utility value of 0.95 was assumed to be applicable until patients reach adulthood (18 years), after which there was no modeled RSV- 
associated impact on utility (sequelae assumed to last 18 years). From 18 years onwards, the simulated cohort had Spanish-specific utilities, which were sourced from Szende et al. [44]. These utility values were 0.982, 0.975, $0.949,0.923,0.901,0.891$, and 0.781 for the age groups 18-24 years, 25-34 years, 35-44 years, $45-54$ years, 5564 years, $65-74$ years, and $75+$ years, respectively.

\section{Costs}

All cost inputs used in the model are presented in Table 3. In line with Spanish guidelines, the analysis considered the societal perspective meaning that both direct and indirect costs were accounted for in the model. Cost data for the economic model were obtained from Spanish national databases and published literature (see Table 3 for references). Furthermore, all costs reported are in 2016 euros $(€)$.

Palivizumab drug costs were estimated based on the average $50 \mathrm{mg}$ ( $€$ 434.91) and $100 \mathrm{mg}(€ 722.19)$ vial consumptions across all administrations. In line with the label of palivizumab, no vial sharing was taken into account. Using local clinical expert input, it was assumed that on average $5 \%$ of the administrations required a $50 \mathrm{mg}$ vial and $95 \%$ of the administrations required a $100 \mathrm{mg}$ vial. To obtain the total cost of prophylaxis, the per-protocol palivizumab costs (five administrations for all children) were adjusted for the actual number of administrations (4.1 injections on average), as reported in Pedraz et al. [45] for Spain.

Hospitalization costs for the first year were calculated by multiplying the daily costs of stay in a pediatric general ward and/or a pediatric ICU by the corresponding numbers of days a patient spent in these wards. It was assumed that all hospitalized patients were admitted to the general ward, whereas only a small group of children were admitted to the ICU. Length of stay in the general ward and ICU, as well as the risk of ICU admission were derived from the recent Spanish CIVIC study [46]. The daily costs of a stay in pediatric general ward and pediatric ICU were derived from Lázaro y de Mercado et al. [19]. It was assumed that the cost associated with MA-RSV was a single GP visit. The cost of a GP visit was derived from Dal Negro et al. [47].

Indirect costs in the first year included lost productivity costs of parents associated with palivizumab administration, for MA-RSV and/or RSV-H children. The cost of lost productivity associated with RSV-H was calculated based on the length of hospital stay. The average wage in Spain (2016 wage) [48], eight working hours per day, and five working days per week were considered.

The cost associated with a nosocomial infection was treated as an indirect cost because nosocomial infections did not directly impact the modeled cohort, i.e. the newly infected, hospitalized children were not part of the initial RSV-H cohort. Based on expert input, cost of two weeks of inpatient stay in a pediatric ward was assumed for the cost per additional child that acquired a nosocomial RSV infection.

UK data on post-hospitalization RSV-associated morbidity indicated that in children with CLD, there was an increase in healthcare resource use attributable to respiratory sequelae for a two-year period after RSV hospitalization [49]. The associated costs were reported at $€ 14,015(€ 17,858$, EUR $1=$ GBP 0.7848, European Central Bank 10 June 2016) per year. Similar cost estimates have not been reported for Spain. Therefore, to account for the increased health care resource use in RSV-H children during their second and third year of life, the UK estimates were rescaled to the Spanish setting. First, by assuming that the RSV-associated respiratory cost is similar in CHD children compared to CLD children, the ratio of the post-hospitalization morbidity costs (i.e. $€ 14,015)$ and the hospitalization costs of the first year (i.e. $€ 19,772$ [ $€ 25,194]$ ) were calculated for the UK (i.e. ratio $=0.71$ ). Second, assuming that the ratio of medical care costs in the second and third year of life versus the first year of life is similar in Spain as in the UK, this ratio was applied to the RSV-hospitalization costs estimated for Spain, eventually yielding Spanishspecific RSV-associated respiratory morbidity costs for the second and third year of life. From the fourth year onwards, yearly costs (both direct and indirect) of respiratory sequelae (asthma and allergic sensitization) were applied in the model for children who developed asthma, sensitization or both $[50,51]$. To avoid doublecounting of post-hospitalization RSV-associated morbidity costs in RSV-H children, asthma and allergic sensitization costs were not applied in the second and third year of life. In MA-RSV children, asthma and allergic sensitization costs were applied from the second year of life onwards.

\section{Analyses}

Future costs and health outcomes were discounted at $3 \%$ in line with the Spanish guideline on economic evaluations of health technologies [52]. The total and incremental life-years (LYs), quality-adjusted life years (QALYs), costs, and the incremental cost-effectiveness ratio (ICER) were estimated. A number of scenario analyses were conducted to test the robustness of the ICER. These scenarios investigated the impact of the following input parameters: model setting parameters (discounting of costs and QALYs, time horizon), clinical parameters (RSV hospitalization probabilities, palivizumab efficacy, case fatality, background mortality, proportion of respiratory sequalae [asthma and/or allergic sensitization], length of respiratory sequelae [asthma and/or allergic sensitization]), utility parameters (baseline utilities, utility decrements 
[RSV-H and sequelae]) and cost parameters (indirect costs, proportion of palivizumab vials used [50 $\mathrm{mg}$ and $100 \mathrm{mg}$ ], length of hospital stay of RSV-H patients, cost of nosocomial infections, increase health care resource utilization). A probabilistic sensitivity analysis (PSA) using 3000 simulations was performed to estimate the simultaneous effect of uncertainty surrounding the model parameters. The results of the PSA were used to simulate the joint distribution of the model outcomes. Cost parameters were assumed to follow a gamma distribution whereas utility and risk parameters were assumed to follow a log normal or beta distribution (Table 1 and Table 3).

\section{Results}

Table 4 presents the base case analysis results, both undiscounted and discounted. Fewer patients in the palivizumab arm had MA-RSV infections and RSV-H when compared to the no prophylaxis arm. Considering a hypothetical cohort of 1000 children, palivizumab prophylaxis was estimated to prevent 62 MA-RSV cases and $44 \mathrm{RSV}-\mathrm{H}$ cases, including 21 delayed surgeries and four immediate surgeries despite the infection. The prevented MA-RSV and RSV-H cases were predicted to result in fewer patients with long-term respiratory sequelae. In the discounted analysis, over a lifetime horizon, incremental QALYs, LYs, and costs were estimated to be $0.11,0.07$, and $€ 1693$, respectively, yielding an ICER of $€ 15,748$ per QALY gained and $€ 24,936$ per LY gained. The corresponding figures in the undiscounted analysis were $0.21,0.17, € 1511, € 7212$ per QALY gained, and $€ 9085$ per LY gained, respectively.

Probabilistic sensitivity analyses demonstrated that the probabilities of palivizumab prophylaxis being costeffective at a threshold of $€ 30,000$ per QALY, $€ 50,000$ per QALY and $€ 100,000$ per QALY were $92.7 \%$, 99.6\% and $100.0 \%$, respectively. Results of all simulations (100\%) fell in the upper right quadrant of the CE plane, denoting both positive incremental QALYs and costs. Simulation results are shown in Fig. 3 (scatter plot of incremental results) and Fig. 4 (cost-effectiveness acceptability curve).

Table 5 presents summary results of the scenario analyses in terms of the ICER per QALY gained. Due to the base case ICER being well below the generally accepted cost-effectiveness threshold, most analyses assessed the detrimental impact of a particular scenario on the ICER. Applying 5\% discount rates (costs and effects), considering a 10-year and 30-year time horizon increased the ICER to $€ 22,009$ per QALY, $€ 33,654$ per QALY, and $€$ 19,307 per QALY, respectively. Model results were also sensitive to various assumptions concerning long-term respiratory sequelae. If allergic sensitization was not considered in the model, the ICER increased to $€ 22,055$ per QALY. Expectedly, the ICERs increased further, when both allergic sensitization and asthma were excluded from the evaluation ( $€$ 28,333 per QALY).

Table 4 Overall survival, quality-adjusted life years and costs per patient, base case analysis

\begin{tabular}{|c|c|c|c|c|c|c|}
\hline & \multicolumn{3}{|c|}{ Undiscounted } & \multicolumn{3}{|l|}{ Discounted } \\
\hline & Palivizumab & No prophylaxis & Difference & Palivizumab & No prophylaxis & Difference \\
\hline Life years & 66.51 & 66.34 & 0.17 & 27.15 & 27.08 & 0.07 \\
\hline Quality-adjusted life years by RSV history & 61.89 & 61.68 & 0.21 & 25.73 & 25.62 & 0.11 \\
\hline No RSV & 57.61 & 51.06 & 6.56 & 23.96 & 21.24 & 2.73 \\
\hline MA-RSV & 1.20 & 5.00 & -3.80 & 0.49 & 2.07 & -1.57 \\
\hline $\mathrm{RSV}-\mathrm{H}$ & 3.08 & 5.63 & -2.55 & 1.27 & 2.31 & -1.05 \\
\hline \multicolumn{7}{|l|}{ Quality-adjusted life years by sequelae history } \\
\hline No Sequelae & 61.28 & 60.25 & 1.03 & 25.25 & 24.51 & 0.74 \\
\hline Asthma & 0.16 & 0.34 & -0.18 & 0.13 & 0.27 & -0.14 \\
\hline Allergic sensitization & 0.33 & 0.84 & -0.51 & 0.26 & 0.66 & -0.40 \\
\hline Asthma and allergic sensitization & 0.12 & 0.24 & -0.12 & 0.09 & 0.19 & -0.10 \\
\hline Costs & $€ 4731$ & $€ 3220$ & $€ 1511$ & $€ 4574$ & $€ 2881$ & $€ 1693$ \\
\hline Prophylaxis costs & $€ 3100$ & $€ 0$ & $€ 3100$ & $€ 3100$ & $€ 0$ & $€ 3100$ \\
\hline MA-RSV: Medical care & $€ 2$ & $€ 9$ & $-€ 7$ & $€ 80$ & $€ 334$ & $€ 254$ \\
\hline MA-RSV: Sequelae & $€ 100$ & $€ 418$ & $€ 318$ & $€ 2$ & $€ 9$ & $-€ 7$ \\
\hline RSV-H: Medical care & $€ 1063$ & $€ 1941$ & $€ 879$ & $€ 1042$ & $€ 1904$ & $-€ 862$ \\
\hline RSV-H: Sequelae & $€ 440$ & $€ 803$ & $-€ 364$ & $€ 326$ & $€ 595$ & $-€ 269$ \\
\hline RSV-H: Nosocomial & $€ 27$ & $€ 49$ & $-€ 22$ & $€ 27$ & $€ 49$ & $€ 22$ \\
\hline
\end{tabular}

Abbreviations: RSV, respiratory syncytial virus; MA-RSV, medically attended RSV infection; RSV-H, RSV infection resulting in hospitalization 


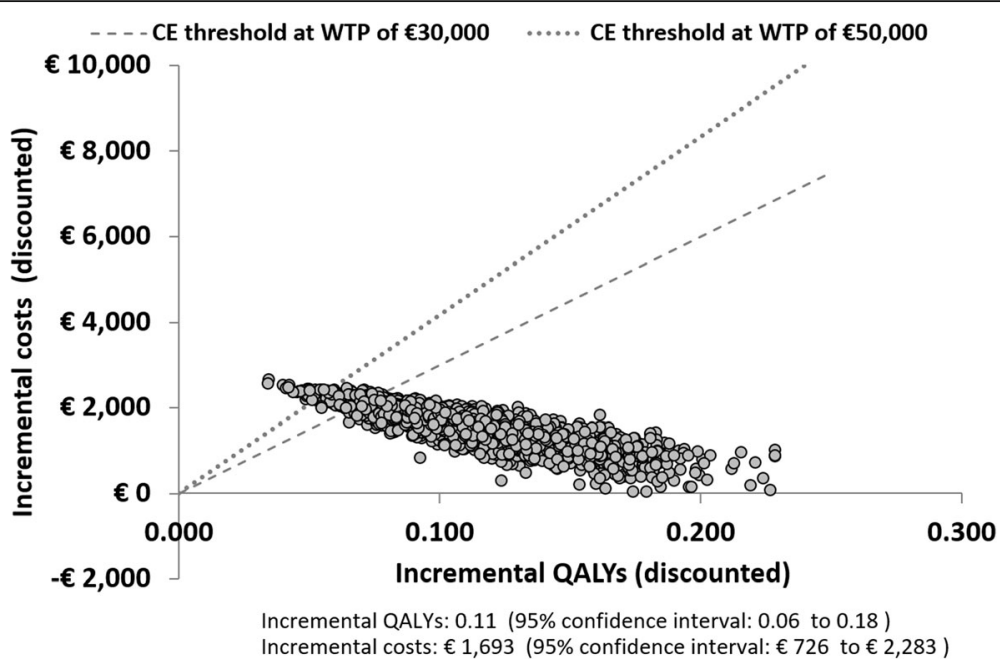

Fig. 3 Scatterplot of incremental cost and incremental QALYs. Abbreviations: CE, cost-effectiveness WTP, willingness to pay; QALY, qualityadjusted life year

Additionally, the model was sensitive to the scenario which assumed that in $90 \%$ of all prophylaxis administrations a $100 \mathrm{mg}$ vial was used whereas in $10 \%$ of all administrations, both, a $50 \mathrm{mg}$ and $100 \mathrm{mg}$ vial was used. This scenario resulted in an increase in the base case ICER to $€ 26,249$ per QALY. Overall, the scenario analyses revealed that the base case ICER was robust to changes in other parameters (e.g. incidence of sequelae, MA-RSV, quality of life). Therefore, it was concluded that palivizumab remained cost-effective even under extreme scenarios.

\section{Discussion}

This current study estimated the cost-utility of palivizumab prophylaxis versus placebo in Spain from the societal perspective, using a novel costeffectiveness model reflecting evidence-based clinical pathways. The base case model results indicated that palivizumab prophylaxis yields additional QALYs and LYs at additional costs. In the discounted analysis, incremental QALYs, LYs, and costs were estimated to be $0.11,0.07$, and $€ 1693$, respectively, yielding an ICER of $€ 15,748$ per QALY gained and $€ 24,936$ per LY gained. The corresponding figures in the undiscounted analysis were $0.21,0.17, € 1511, € 7212$ per QALY gained, and $€ 9085$ per LY gained, respectively. Probabilistic sensitivity analyses demonstrated that the probability of palivizumab prophylaxis being cost-effective at a $€ 30,000$ per QALY threshold was $92.7 \%$.

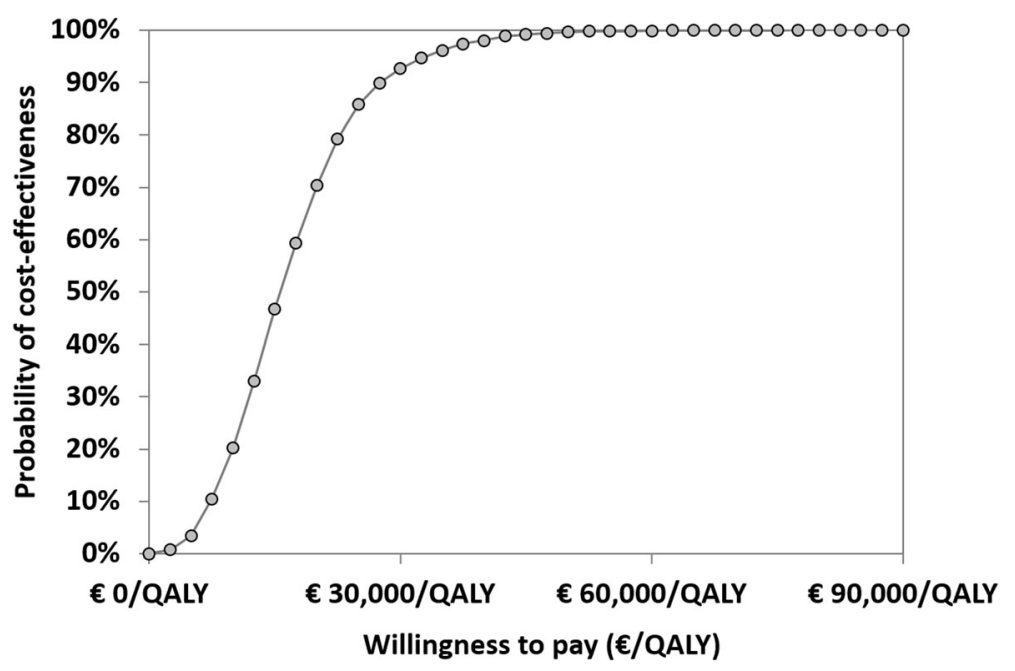

Fig. 4 Cost-effectiveness acceptability curve. Abbreviations: QALY, quality-adjusted life year 
Table 5 Results of the scenario analyses, incremental costs, outcomes, and incremental cost-effectiveness ratios

\begin{tabular}{|c|c|c|c|c|c|}
\hline Scenario & Incremental costs & Incremental QALYs & Incremental LYs & ICER (QALYs) & ICER (LYS) \\
\hline Base case scenario & $€ 1693$ & 0.11 & 0.07 & $€ 15,748$ & $€ 24,936$ \\
\hline \multicolumn{6}{|l|}{ Model setting parameters } \\
\hline Discount rate: $1.5 \%$ & $€ 1610$ & 0.14 & 0.10 & $€ 11,252$ & $€ 16,005$ \\
\hline Discount rate: $5 \%$ & $€ 1783$ & 0.08 & 0.05 & $€ 22,009$ & $€ 38,971$ \\
\hline Time horizon: 10 years & $€ 1693$ & 0.05 & 0.02 & $€ 33,654$ & $€ 77,789$ \\
\hline Time Horizon: 30 years & $€ 1693$ & 0.09 & 0.05 & $€ 19,307$ & $€ 36,405$ \\
\hline \multicolumn{6}{|l|}{ Clinical parameters } \\
\hline 10\% (relative) lower RSV-H rate & $€ 1808$ & 0.10 & 0.06 & $€ 18,364$ & $€ 29,595$ \\
\hline $\begin{array}{l}\text { Palivizumab efficacy (RSV-H) at lower 95\% confidence } \\
\text { interval limit }\end{array}$ & $€ 1916$ & 0.09 & 0.05 & $€ 21,300$ & $€ 35,024$ \\
\hline $\begin{array}{l}\text { Palivizumab efficacy (RSV-H) at upper 95\% confidence } \\
\text { interval limit }\end{array}$ & $€ 1415$ & 0.13 & 0.08 & $€ 10,952$ & $€ 16,805$ \\
\hline Case fatality based on Wang et al. (3.72\%) [54] & $€ 1673$ & 0.09 & 0.05 & $€ 18,720$ & $€ 34,629$ \\
\hline Case fatality $+1 \%$ higher in no prophylaxis group & $€ 1721$ & 0.13 & 0.10 & $€ 12,841$ & $€ 17,825$ \\
\hline No general population background mortality in 1st year & $€ 1572$ & 0.11 & 0.07 & $€ 14,133$ & $€ 23,155$ \\
\hline Allergic sensitization excluded & $€ 1923$ & 0.09 & 0.07 & $€ 22,055$ & $€ 28,328$ \\
\hline All respiratory sequelae excluded & $€ 2209$ & 0.08 & 0.07 & $€ 28,333$ & $€ 32,545$ \\
\hline Length of respiratory sequelae 6 years & $€ 2020$ & 0.09 & 0.07 & $€ 23,512$ & $€ 29,764$ \\
\hline Length of respiratory sequelae 12 years & $€ 1841$ & 0.10 & 0.07 & $€ 18,843$ & $€ 27,125$ \\
\hline Length of respiratory sequelae 24 years & $€ 1569$ & 0.12 & 0.07 & $€ 13,574$ & $€ 23,118$ \\
\hline Length of respiratory sequelae: lifetime & $€ 1094$ & 0.15 & 0.07 & $€ 7446$ & $€ 16,112$ \\
\hline Proportion of respiratory sequelae: $+5 \%$ & $€ 1584$ & 0.11 & 0.07 & $€ 14,054$ & $€ 23,344$ \\
\hline Proportion of respiratory sequelae: $-5 \%$ & $€ 1801$ & 0.10 & 0.07 & $€ 17,616$ & $€ 26,529$ \\
\hline \multicolumn{6}{|l|}{ Utility parameters } \\
\hline No utility decrement for RSV-H & $€ 1693$ & 0.11 & 0.07 & $€ 15,947$ & $€ 24,936$ \\
\hline No utility decrement for allergy & $€ 1693$ & 0.09 & 0.07 & $€ 19,414$ & $€ 24,936$ \\
\hline No utility decrement for asthma & $€ 1693$ & 0.10 & 0.07 & $€ 17,224$ & $€ 24,936$ \\
\hline \multicolumn{6}{|l|}{ Cost parameters } \\
\hline $\begin{array}{l}\text { Indirect costs associated with prophylaxis and } \\
\text { hospitalization excluded }\end{array}$ & $€ 1552$ & 0.11 & 0.07 & $€ 14,441$ & $€ 22,867$ \\
\hline $\begin{array}{l}\text { Palivizumab cost: Proportions of } 50 \mathrm{mg} \text { and } 100 \mathrm{mg} \\
\text { vial use equal to } 0 \% \text { and } 100 \% \text {, respectively }\end{array}$ & $€ 1751$ & 0.11 & 0.07 & $€ 16,295$ & $€ 25,804$ \\
\hline $\begin{array}{l}\text { Palivizumab cost: Proportion of } 100 \mathrm{mg} \text { and } 50 \mathrm{mg}+100 \\
\text { mg vial use, equals to } 90 \% \text { and } 10 \% \text {, respectively }\end{array}$ & $€ 1930$ & 0.11 & 0.07 & $€ 17,954$ & $€ 28,431$ \\
\hline $\begin{array}{l}\text { Palivizumab cost: Proportion of } 100 \mathrm{mg} \text { and } 50 \mathrm{mg}+100 \\
\text { mg vial use, equals to } 40 \% \text { and } 60 \% \text {, respectively }\end{array}$ & $€ 2821$ & 0.11 & 0.07 & $€ 26,249$ & $€ 41,566$ \\
\hline $\begin{array}{l}\text { Length of stay associated with RSV-H based on the pivotal } \\
\text { trial ( } 12.4 \text { days pediatric ward, } 38.1 \% \text { ICU admission, } 15.2 \\
\text { days ICU) [16] }\end{array}$ & $€ 1118$ & 0.11 & 0.07 & $€ 10,402$ & $€ 16,471$ \\
\hline $\begin{array}{l}\text { Indirect costs associated with prophylaxis, hospitalization, } \\
\text { and respiratory sequelae excluded }\end{array}$ & $€ 1223$ & 0.11 & 0.07 & $€ 11,374$ & $€ 18,010$ \\
\hline Costs associated with nosocomial infections excluded & $€ 1715$ & 0.11 & 0.07 & $€ 15,954$ & $€ 25,263$ \\
\hline Exclude delayed surgeries pathway from decision tree & $€ 1855$ & 0.11 & 0.07 & $€ 17,261$ & $€ 27,332$ \\
\hline Increased HCU in RSV-H: 0 years & $€ 2027$ & 0.11 & 0.07 & $€ 18,861$ & $€ 29,866$ \\
\hline Increased HCU in RSV-H: 4 years & $€ 1860$ & 0.21 & 0.17 & $€ 8882$ & $€ 11,189$ \\
\hline
\end{tabular}

Abbreviations: QALYs, quality-adjusted life years; LY, life years; ICER, incremental cost-effectiveness ratio; RSV, respiratory syncytial virus; RSV-H, RSV infection resulting in hospitalization; ICU, intensive care unit; $\mathrm{HCU}$, health care resource use 
A recent review of cost-effectiveness studies assessing palivizumab versus no prophylaxis in children with $\mathrm{CHD}$ summarized the currently available evidence [53]. This literature review found that only four economic evaluations focused solely on the CHD subpopulation [24-27]. However, several additional analyses examined CHD populations in conjunction with other high-risk subgroups [21, 40, 41, 54-56]. The studies included in the review were fairly recent; most assessments were published in or after 2008 [21, 24, 40, 54-56] and covered a number of countries including Germany [24], the UK $[27,41]$, and the US $[26,56]$. Most studies were based on a cost-utility analysis, i.e., the incremental cost per additional QALY was estimated; however, one evaluation assessed the incremental costs of a prevented hospitalization [25]. In each study, the model structure was based on the design and primary outcome of the pivotal trial $[2,16]$, so that the reduction of RSV-related hospitalization by palivizumab prophylaxis could be directly reflected. Thus, models typically included RSV hospitalization and non-hospitalization health states. Frequently, the health state capturing RSV hospitalization considered days spent in both ICU and the general pediatric ward. If the cost-effectiveness of palivizumab was assessed in multiple risk groups (e.g. children with CHD and children with CLD), the same model structure was assumed to be applicable to all considered subgroups. None of the studies explicitly incorporated the risk of complicated and delayed surgery due to RSV infection in children with CHD, nor did they consider the risk of MA-RSV infection. Some of the studies took account of the risk of long-term sequelae in children with history of RSV-hospitalization [21, 40, 41, 54, 55]. These studies typically included asthma as the single respiratory sequelae and assumed that it persisted for a limited number of years [21, 40, 41, 54,55]. While our study adopted the approach used in previous studies that modeled the impact of respiratory sequelae, we used two additional sources $[29,36]$ to model asthma and allergic sensitization sequelae, linked to MA-RSV. Case fatality rates during RSV hospitalization varied markedly across the studies [21, 24-27, 40, 41, 54-56]. Many studies used a lower case fatality rate for patients who received palivizumab prophylaxis than for those who did not, i.e., in these studies palivizumab prophylaxis was assumed to reduce the risk of case fatality [21, 24, 26, 27, 40, 41, 54-56]. For the current model, equal case fatality rates were applied for children hospitalized for RSV infection.

While the model presented in this paper better reflects clinical pathways compared to past models, there are a number of limitations that need to be considered in the interpretation of the results. One of the limitations is the lack of available recent randomized trial based efficacy data for palivizumab in children with CHD in Spain. In particular, rates of RSV-H utilized in the model were limited to the pivotal RCTs conducted in a multinational setting more than a decade ago. One can speculate that RSV-H rates in children with $\mathrm{CHD}$ may have changed over time, perhaps due to improved socioeconomic or other environmental conditions. The impact of such a scenario was assessed in a deterministic analysis (i.e. assuming $10 \%$ relative lower $\mathrm{RSV}-\mathrm{H}$ rate keeping the efficacy of prophylaxis constant); however, the impact of lower RSV-H rate on the ICER was limited and the conclusion of the study did not change. Additionally, decreasing trends of RSV-H rates have not been confirmed for children with CHD in Spain specifically. In contrast, the available evidence from a retrospective study of hospitalizations for RSV bronchiolitis in children aged $<1$ year, using nationally representative data for Spain, suggest that RSV-H rates did not decrease over the 2004-2012 assessment period [57]. Overall, given the lack of evidence on decreasing RSV-H rates, it is believed that the model used the best available information in this respect. Another limitation of the study was associated with the available evidence on palivizumab drug costs in Spain. A sophisticated drug cost calculation approach was presented in a previous economic evaluation for the UK, where palivizumab costs were estimated by the required dose, i.e., the number of $100-\mathrm{mg}$ or $50-\mathrm{mg}$ vials needed to administer palivizumab each month [17]. The initial dose was calculated using the infants' average weight at the start of prophylaxis as reported in the pivotal trial $(6.1 \mathrm{~kg})$. Infants' average weight at each subsequent administration was then estimated using UK-specific WHO growth chart data accounting for the preterm birth. The approach predicted that in $60 \%$ of the administrations both a $100-\mathrm{mg}$ and a $50-\mathrm{mg}$ vial would be required. While this approach predicted an ICER of $€ 26,249$ per QALY within the present model framework (please see Table 5), based on local expert opinion it was concluded that the baseline average weight and the applied growth rates do not represent the Spanish setting; these would overestimate the required dose and consequently palivizumab drug costs. To adjust for the lower weight of Spanish infants compared to infants from participating countries of the trial (e.g. US, UK, and Germany), an expert opinion-based drug cost calculation approach was employed. The expert indicated that in $5 \%$ of all cases of palivizumab administrations a $50-\mathrm{mg}$ vial was used and in $95 \%$ of all cases of palivizumab administrations a $100-\mathrm{mg}$ vial was used (i.e. in no case were a 50-mg vial and 100-mg vial used, in combination, for a single administration). There is ample evidence demonstrating that the Spanish population is shorter and hence are likely to weigh less than the US, the UK or German populations [58]. 
Furthermore, it has been documented that children with CHD experience a decreased growth trajectory compared with their peers [59]; therefore, applying growth rates for drug cost calculations that represent the overall population might not be clinically plausible. Another possible limitation of the present study was the way case fatality and CHD-specific background mortality were applied. Both were applied during the first year of the simulation (i.e. in the decision tree). However, the case fatality was sourced from a study that examined children with CHD hospitalized for severe RSV LRTI [31] and may thus already include mortality due to $\mathrm{CHD}$ in addition to mortality due to an RSV infection. Although the same case fatality was used for the prophylaxis arm and placebo arm, there is a possibility of double counting. To assess the potential impact, a scenario analysis was conducted to investigate the effect of implementing CHD-specific background mortality, starting from the second year onwards, so that there was no overlap. Results show that the discounted ICER decreased to $€$ 14,133 per QALY (Table 5), thus, revealing that the approach that was taken in the base case analysis was conservative. Furthermore, another limitation of the model was related to the long-term respiratory sequelae incorporated into the model. In the base case analysis, it was assumed that children who developed asthma or allergic sensitization were affected by these conditions until the age of 18 and not afterwards. While the assumption that respiratory sequelae have a fixed duration was based on previous cost-effectiveness models presented in peer-reviewed publications $[29,54,55,60]$, one may argue that the duration of asthma or allergic sensitization lasts longer (or potentially shorter) than 18 years. Sensitivity analyses were conducted to test the impact of respiratory sequelae on the model results. It was found that the ICER changed moderately in response to various assumptions on the duration of respiratory sequelae. However, even in the extreme scenario when no respiratory sequela were taken into account, the ICER remained below the $€ 30,000$ per QALY threshold.

\section{Conclusion}

In conclusion, the cost-utility analysis using a novel model reflecting evidence-based clinical pathways demonstrated that the high efficacy of palivizumab prophylaxis compared to no prophylaxis resulted in a substantial number of prevented hospitalizations and generated a high number of QALYs gained. Although based on a single trial and associated with uncertainty, there is clear evidence that palivizumab prophylaxis represents a cost-effective treatment option in children with CHD according to generally accepted standards of cost-effectiveness in Spain.

\section{Abbreviations}

AS: Allergic sensitization; CHD: Congenital heart disease; CLD: Chronic lung disease; HRQoL: Health-related quality of life; HUI: Health Utilities Index; ICER: Incremental cost-effectiveness ratio; ICU: Intensive care unit; LRTI: Lower respiratory tract infections; LYS: Life-years; MA-RSV: Medically attended RSV infection; PSA: Probabilistic sensitivity analysis; QALYs: Quality-adjusted life years; RRR: Relative risk reduction; RSV: Respiratory syncytial virus; RSV-H: RSV hospitalization; SE: Standard error; SMR: Standardized mortality ratio; UK: United Kingdom; US: Unites States; WTP: Willingness to pay

\section{Acknowledgements}

We would like to thank Marieke Heisen and Amrita Ostawal, Pharmerit International for their assistance with the editing of this manuscript.

\section{Funding}

Financial support for this study was provided by a grant from AbbVie. The funding agreement ensured the authors' independence in designing the study, interpreting the data, writing, and publishing the report.

\section{Authors' contributions}

RS, IM, NGR, ARB and EG helped to conceptualize the model design and constructed the model. In addition, they either gave guidance on the analyses (NGR, ARB, EG) or conducted the analyses (RS, IM). CML, an expert in the disease field, helped to validate the model structure. All authors read and approved the final manuscript.

\section{Competing interest}

Employees of Pharmerit International were paid consultants to AbbVie for performing the described research and have no conflict of interest to report. NGR, ARB and EG are employees of AbbVie and may hold AbbVie stock. The authors attest that any and all financial or other relationships, including financial support of the study that could be construed as a conflict of interest have been disclosed here. All authors have read and approved the final draft of the manuscript.

\section{Publisher's Note}

Springer Nature remains neutral with regard to jurisdictional claims in published maps and institutional affiliations.

\section{Author details}

${ }^{1}$ Pharmerit International, Health Economics and Outcomes Research, Zimmerstraße 55, 10117 Berlin, Germany. ${ }^{2}$ Pharmerit International, Health Economics and Outcomes Research, Rotterdam, the Netherlands. ${ }^{3}$ AbbVie, Medical Department, Madrid, Spain. ${ }^{4}$ AbbVie, Government Affairs and Market Access, Madrid, Spain. ${ }^{5}$ AbbVie, Health Economics and Outcomes Research, Chicago, IL, USA. 'Pediatric Cardiology, Gregorio Marañón University Hospital, Madrid, Spain.

Received: 2 May 2017 Accepted: 13 November 2017

Published online: 19 December 2017

\section{References}

1. Simoes EA, Carbonell-Estrany X. Impact of severe disease caused by respiratory syncytial virus in children living in developed countries. Pediatr Infect Dis J [Internet]. 2003 Feb [cited 2013 Aug 6];22(2 Suppl):S13-8-20. Available from: http://www.ncbi.nlm.nih.gov/pubmed/12671448.

2. Mullins JA, Lamonte AC, Bresee JS, Anderson L. Substantial variability in community respiratory syncytial virus season timing. Pediatr Infect Dis J [Internet]. 2003 Oct [cited 2013 Aug 6];22(10):857-862. Available from: http://www.ncbi.nlm.nih.gov/pubmed/14551484.

3. Nair H, Nokes DJ, Gessner BD, Dherani M, Madhi SA, Singleton RJ, et al. Global burden of acute lower respiratory infections due to respiratory syncytial virus in young children: a systematic review and meta-analysis. Lancet [Internet]. 2010 May 1 [cited 2013 Aug 6];375(9725):1545-1555. Available from: http://www.pubmedcentral.nih.gov/articlerender.fcgi?artid= 2864404\&tool=pmcentrez\&rendertype=abstract

4. Domachowske JB, Rosenberg HF. Respiratory syncytial virus infection: immune response, immunopathogenesis, and treatment. Clin Microbiol Rev [Internet]. 1999 Apr [cited 2013 Oct 10];12(2):298-309. Available from: http://www.pubmedcentral.nih.gov/articlerender.fcgi?artid= 88919\&tool=pmcentrez\&rendertype=abstract 
5. Gil-Prieto R, Gonzalez-Escalada A, Marín-García P, Gallardo-Pino C, Gil-deMiguel A. Respiratory Syncytial Virus Bronchiolitis in Children up to 5 Years of Age in Spain. Medicine (Baltimore) [Internet]. 2015 May;94(21):e831. Available from: http://content.wkhealth.com/linkback/openurl?sid=WKPTLP: landingpage\&an=00005792-201505050-00011

6. Hall CB, Weinberg GA, Iwane MK, Blumkin AK, Edwards KM, Staat MA, et al. The burden of respiratory syncytial virus infection in young children. $\mathrm{N}$ Engl J Med [Internet]. 2009 Feb 5;360(6):588-98. Available from: http://www. nejm.org/doi/abs/10.1056/NEJMoa0804877

7. Deshpande SA. The clinical and health economic burden of respiratory syncytial virus disease among children under 2 years of age in a defined geographical area. Arch Dis Child [Internet]. 2003 Dec 1;88(12):1065-9. Available from: http://adc.bmj.com/cgi/doi/10.1136/adc.88.12.1065

8. Bont L, Checchia PA, Fauroux B, Figueras-Aloy J, Manzoni P, Paes B, et al. Defining the epidemiology and burden of severe respiratory syncytial virus infection among infants and children in western countries. Infect Dis Ther [Internet]. 2016 Sep 1;5(3):271-98. Available from: http://link.springer.com/10. 1007/s40121-016-0123-0

9. Figueras Aloy J, Quero J. Recomendaciones para la prevención de la infección por virus respiratorio sincitial. An Pediatría [Internet]. 2005 Oct; 63(4):357-62. Available from: http://linkinghub.elsevier.com/retrieve/pii/ S169540330570206X

10. Figueras Aloy J, Carbonell EX. Actualización de las recomendaciones de la Sociedad Española de Neonatología para la utilización del palivizumab como profilaxis de las infecciones graves por el virus respiratorio sincitial. An Pediatría [Internet]. 2015 Mar;82(3):199.e1-2. Available from: http://linkinghub.elsevier. com/retrieve/pii/S1695403314004615

11. Medrano López C, García-Guereta L, Fernández Pineda L, Malo Concepción P, Maroto Álvaro E, Santos de Soto J, et al. Consenso clínico sobre la profilaxis de la infección por virus respiratorio sincitial y el uso del palivizumab en cardiología pediátrica. An Pediatría [Internet]. 2010 Jun;72(6):432.e1-432.e13. Available from: http://linkinghub.elsevier.com/retrieve/pii/S1695403310001542

12. Andabaka T, Nickerson JW, Rojas-Reyes MX, Rueda JD, Bacic Vrca V, Barsic B. Monoclonal antibody for reducing the risk of respiratory syncytial virus infection in children. Cochrane database Syst Rev [Internet]. 2013 Jan [cited 2013 Aug 6];4:CD006602. Available from: http://www.ncbi.nlm.nih.gov/ pubmed/23633336.

13. European Medicines Agency (EMA). Summary of Product Characteristics Synagis 50 mg (palivizumab) [Internet]. 2009 [cited 2017 Nov 7]. Available from: http://www.ema.europa.eu/docs/en_GB/document_library/EPAR_-Product_Information/human/000257/WC500056908.pdf

14. Palivizumab, a humanized respiratory syncytial virus monoclonal antibody, reduces hospitalization from respiratory syncytial virus infection in high-risk infants. The IMpact-RSV Study Group. Pediatrics [Internet]. 1998 Sep [cited 2013 Aug 8];102(3 Pt 1):531-7. Available from: http://www.ncbi.nlm.nih.gov/ pubmed/9738173

15. Blanken MO, Rovers MM, Molenaar JM, Winkler-Seinstra PL, Meijer A, Kimpen $J$, et al. Respiratory syncytial virus and recurrent wheeze in healthy preterm infants. N Engl J med [internet]. 2013/05/10. 2013;368(19):1791-1799. Available from: http://www.ncbi.nlm.nih.gov/pubmed/23656644.

16. Feltes TF, Cabalka AK, Meissner HC, Piazza FM, Carlin DA, Top FH, et al. Palivizumab prophylaxis reduces hospitalization due to respiratory syncytial virus in young children with hemodynamically significant congenital heart disease. J Pediatr [Internet]. 2003 Oct;143(4):532-40. Available from: http://www.ncbi.nlm.nih.gov/pubmed/14571236

17. Bentley A, Filipovic I, Gooch K, Büsch K. A cost-effectiveness analysis of respiratory syncytial virus (RSV) prophylaxis in infants in the United Kingdom. Health Econ Rev [Internet]. 2013 Jan [cited 2014 Apr 18];3(1):18. Available from: http://www.pubmedcentral.nih.gov/articlerender.fcgi?artid= 3735492\&tool=pmcentrez\&rendertype=abstract

18. Chirico G, Ravasio R, Sbarigia U. Cost-utility analysis of palivizumab in Italy: results from a simulation model in the prophylaxis of respiratory syncytial virus infection (RSV) among high-risk preterm infants. Ital J Pediatr [Internet]. 2009 Jan [cited 2013 Apr 16];35(1):4. Available from: http://www.pubmedcentral.nih. gov/articlerender.fcgi?artid=2687544\&tool=pmcentrez\&rendertype=abstract

19. Lázaro Y De Mercado P, Figueras Aloy J, Doménech Martínez E, Echániz Urcelay I, Closa Monasterolo R, Wood Wood MA, et al. The efficiency (costeffectiveness) of palivizumab as prophylaxis against respiratory syncytial virus infection in premature infants with a gestational age of 32-35 weeks in Spain. An Pediatr (Barc) [Internet]. 2006 Oct [cited 2014 Jul 16];65(4):316-324. Available from: http://www.ncbi.nlm.nih.gov/pubmed/17020726.
20. Meijboom MJ, Rozenbaum MH, Benedictus A, Luytjes W, Kneyber MCJ, Wilschut JC, et al. Cost-effectiveness of potential infant vaccination against respiratory syncytial virus infection in The Netherlands. Vaccine [Internet]. 2012 Jun;30(31):4691-700. Available from: http://linkinghub.elsevier.com/ retrieve/pii/S0264410X12006184

21. Resch B, Gusenleitner W, Nuijten MJC, Lebmeier M, Wittenberg W. Costeffectiveness of palivizumab against respiratory syncytial viral infection in high-risk children in Austria. Clin Ther [Internet]. 2008 Apr;30(4):749-760. Available from: http://www.ncbi.nlm.nih.gov/pubmed/18498923.

22. Salinas-Escudero G, Martínez-Valverde S, Reyes-López A, Garduño-Espinosa J, Muñoz-Hernández O, Granados-García V, et al. Cost-effectiveness analysis of the use of palivizumab in the prophylaxis of preterm patients in Mexico. Salud Publica Mex [internet]. 2012;54(1):47-59. Available from: http://www. ncbi.nlm.nih.gov/pubmed/22286828.

23. Weiner LB, Masaquel AS, Polak MJ, Mahadevia PJ. Cost-effectiveness analysis of palivizumab among pre-term infant populations covered by Medicaid in the United States. J Med Econ [Internet]. 2012 Oct 21;15(5):997-1018. Available from: http://www.tandfonline.com/doi/full/10.3111/13696998.2012.672942

24. Nuijten $\mathrm{M}$, Lebmeier $\mathrm{M}$, Wittenberg $\mathrm{W}$. Cost effectiveness of palivizumab in children with congenital heart disease in Germany. J Med Econ [Internet]. 2009 Jan [cited 2013 Apr 16];12(4):301-308. Available from: http://www.ncbi. nlm.nih.gov/pubmed/19811110.

25. Harris KC, Anis AH, Crosby MC, Cender LM, Potts JE, Human DG. Economic evaluation of palivizumab in children with congenital heart disease: a Canadian perspective. Can J Cardiol [internet]. 2011 [cited 2013 Aug 13];27(4): 523.e11-5. Available from: http://www.ncbi.nlm.nih.gov/pubmed/21664100.

26. Yount LE, Mahle WT. Economic analysis of palivizumab in infants with congenital heart disease. Pediatrics [Internet]. 2004 Dec [cited 2013 Apr 16]; 114(6):1606-1611. Available from: http://www.ncbi.nlm.nih.gov/pubmed/ 15574622.

27. Rackham OJ, Thorburn K, Kerr SJ. The potential impact of prophylaxis against bronchiolitis due to the respiratory syncytial virus in children with congenital cardiac malformations. Cardiol Young [Internet]. 2005 Jun;15(3): 251-255. Available from: http://www.ncbi.nlm.nih.gov/pubmed/15865826.

28. Díez-Domingo J, Pérez-Yarza EG, Melero JA, Sánchez-Luna M, Aguilar MD, Blasco AJ, et al. Social, economic, and health impact of the respiratory syncytial virus: a systematic search. BMC Infect Dis [Internet]. 2014 Oct 30;14: 544. Available from: http://www.ncbi.n/m.nih.gov/pubmed/25358423.

29. Sigurs N, Aljassim F, Kjellman B, Robinson PD, Sigurbergsson F, Bjarnason R, et al. Asthma and allergy patterns over 18 years after severe RSV bronchiolitis in the first year of life. Thorax [Internet]. 2010 Dec [cited 2013 Aug 12];65(12):1045-52. Available from: http://www.ncbi.nlm.nih.gov/ pubmed/20581410.

30. Altman CA, Englund JA, Demmler G, Drescher KL, Alexander MA, Watrin C, et al. Respiratory syncytial virus in patients with congenital heart disease: a contemporary look at epidemiology and success of preoperative screening. Pediatr Cardiol [Internet]. 2000 [cited 2013 Nov 29];21(5):433-438. Available from: http://www.ncbi.nlm.nih.gov/pubmed/10982701.

31. Szabo SM, Gooch KL, Bibby MM, Vo PG, Mitchell I, Bradt P, et al. The risk of mortality among young children hospitalized for severe respiratory syncytial virus infection. Paediatr Respir Rev [Internet]. 2013 Jan [cited 2013 Oct 9];13 Suppl 2:S1-S8. Available from: http://www.ncbi.nlm.nih.gov/pubmed/ 23269181.

32. Tennant PW, Pearce MS, Bythell M, Rankin J. 20-year survival of children born with congenital anomalies: a population-based study. Lancet [Internet]. 2010 Feb;375(9715):649-56. Available from: http://linkinghub. elsevier.com/retrieve/pii/S014067360961922X

33. University of California, B.U., and Max Planck Institute for Demographic Research (Germany), Human Mortality Database. 2012;University of California, Berkeley, and Max Planck.

34. Diller G-P, Kempny A, Alonso-Gonzalez R, Swan L, Uebing A, Li W, et al. Survival prospects and circumstances of death in contemporary adult congenital heart disease patients under follow-up at a large tertiary CentreCLINICAL PERSPECTIVE. Circulation [Internet]. 2015 Dec 1;132(22): 2118-25. Available from: http://circ.ahajournals.org/lookup/doi/10.1161/ CIRCULATIONAHA.115.017202

35. Simões EAF, Carbonell-Estrany X, Rieger CHL, Mitchell I, Fredrick L, Groothuis JR. The effect of respiratory syncytial virus on subsequent recurrent wheezing in atopic and nonatopic children. J Allergy Clin Immunol [Internet]. 2010 Aug [cited 2013 Aug 12];126(2):256-262. Available from: http://www.ncbi.nlm.nih. gov/pubmed/20624638. 
36. Stein RT, Sherrill D, Morgan WJ, Holberg CJ, Halonen M, Taussig LM, et al. Respiratory syncytial virus in early life and risk of wheeze and allergy by age 13 years. Lancet [Internet]. 1999 Aug 14 [cited 2013 Nov 29];354(9178):541-545. Available from: http://www.ncbi.n/m.nih.gov/pubmed/10470697.

37. Ehlken B, Ihorst G, Lippert B, Rohwedder A, Petersen G, Schumacher M, et al. Economic impact of community-acquired and nosocomial lower respiratory tract infections in young children in Germany. Eur J Pediatr [Internet]. 2005 Oct;164(10):607-15. Available from: http://link.springer.com/ 10.1007/s00431-005-1705-0

38. Greenough A, Alexander J, Burgess S, Bytham J, Chetcuti PAJ, Hagan J, et al. Health care utilisation of prematurely born, preschool children related to hospitalisation for RSV infection. Arch Dis Child [Internet]. 2004 Jul [cited 2013 Aug 8];89(7):673-678. Available from: http://www.pubmedcentral.nih. gov/articlerender.fcgi?artid=1720002\&tool=pmcentrez\&rendertype=abstract

39. Wang D, Bayliss S, Meads C. Palivizumab for immunoprophylaxis of respiratory syncytial virus (RSV) bronchiolitis in high-risk infants and young children: a systematic review and additional economic modelling of subgroup analyses. Health Technol Assess [Internet]. 2011 Jan [cited 2013 Dec 3];15(5):iii-iv, 1-124. Available from: http://www.ncbi.n/m.nih.gov/pubmed/21281564.

40. Resch B, Sommer C, Nuijten MJC, Seidinger S, Walter E, Schoellbauer V, et al. Cost-effectiveness of Palivizumab for Respiratory Syncytial Virus Infection in High-risk Children, Based on Long-term Epidemiologic Data From Austria. Pediatr Infect Dis J [Internet]. 2012 Jan [cited 2013 Apr 24];31(1):e1-e8. Available from: http://www.ncbi.nlm.nih.gov/pubmed/21960187.

41. Nuijten MJC, Wittenberg W, Lebmeier M. Cost effectiveness of palivizumab for respiratory syncytial virus prophylaxis in high-risk children: a UK analysis. Pharmacoeconomics [internet]. 2007;25(1):55-71. Available from: http://www. ncbi.nlm.nih.gov/pubmed/17192118.

42. Briggs AH, Bousquet J, Wallace M V, Busse WW, Clark TJH, Pedersen SE, et al. Cost-effectiveness of asthma control: an economic appraisal of the GOAL study. Allergy [Internet]. 2006 May [cited 2013 Nov 23];61(5):531-536. Available from: http://www.ncbi.nlm.nih.gov/pubmed/16629780.

43. Brüggenjürgen $B$, Reinhold T, Brehler R, Laake E, Wiese G, Machate U, et al. Cost-effectiveness of specific subcutaneous immunotherapy in patients with allergic rhinitis and allergic asthma. Ann Allergy Asthma Immunol [Internet]. 2008 Sep [cited 2013 Apr 2];101(3):316-324. Available from: http://www. ncbi.nlm.nih.gov/pubmed/18814456.

44. Szende A, Janssen B, Cabases J. Self-reported population health: an international perspective based on EQ-5D [internet]. Dordrecht: Springer Netherlands; 2014. Available from: http://link.springer.com/10.1007/97894-007-7596-1

45. Pedraz C, Carbonell-Estrany X, Figueras-Aloy J, Quero J. Effect of palivizumab prophylaxis in decreasing respiratory syncytial virus hospitalizations in premature infants. Pediatr Infect Dis J [Internet]. 2003 Sep [cited 2014 Jul 16];22(9):823-827. Available from: http://www.ncbi.nlm.nih.gov/pubmed/14506376.

46. Medrano López C, García-Guereta L. Community-acquired respiratory infections in young children with congenital heart diseases in the palivizumab era: the Spanish 4-season civic epidemiologic study. Pediatr Infect Dis J [Internet]. 2010 Dec [cited 2014 Jul 16];29(12):1077-1082. Available from: http://www.ncbi.nlm.nih.gov/pubmed/20686437.

47. Dal Negro R, Piskorz P, Vives R, Guilera M, Sazonov Kocevar V, Badia X. Healthcare utilisation and costs associated with adding montelukast to current therapy in patients with mild to moderate asthma and co-morbid allergic rhinitis: PRAACTICAL study. Pharmacoeconomics [Internet]. 2007 Jan [cited 2014 Jul 16];25(8):665-76. Available from: http://www.ncbi.nlm.nih. gov/pubmed/17640108.

48. Instituto Nacional de Estadística. 8.3. Costes laborales y salarios. In: Anuario Estadístico de España. 2017th ed. Madrid: Instituto Nacional de Estadística; 2017. p. 235-268.

49. Shefali-Patel D, Paris MA, Watson F, Peacock JL, Campbell M, Greenough A. RSV hospitalisation and healthcare utilisation in moderately prematurely born infants. Eur J Pediatr [Internet]. 2012 Jul [cited 2013 Dec 2];171(7): 1055-1061. Available from: http://www.ncbi.nlm.nih.gov/pubmed/22302458.

50. Blasco Bravo AJ, Pérez-Yarza EG, De Mercado PLY, Perales AB, Díaz Vazquez CA, Moreno GA. Coste del asma en pediatría en España: un modelo de evaluación de costes basado en la prevalencia. An Pediatr. 2011;74:145-53.

51. Smith AF, Pitt AD, Rodruiguez AE, Alio JL, Marti N, Teus M, et al. The economic and quality of life impact of seasonal allergic conjunctivitis in a Spanish setting. Ophthalmic Epidemiol [Internet]. 2005 Aug [cited 2014 Jul 16];12(4):233-42. Available from: http://www.ncbi.nlm.nih.gov/pubmed/ 16033744.
52. López-Bastida J, Oliva J, Antoñanzas F, García-Altés A, Gisbert R, Mar J, et al. Spanish recommendations on economic evaluation of health technologies. Eur J Health Econ. 2010 Oct; 11(5):513-20.

53. Hussman JM, Lanctôt $\mathrm{KL}$, Paes $\mathrm{B}$. The cost effectiveness of palivizumab in congenital heart disease: a review of the current evidence. J Med Econ [Internet]. 2013 Jan [cited 2013 Apr 5];16(1):115-124. Available from: http://www.ncbi.nlm.nih.gov/pubmed/23016567.

54. Wang D, Cummins C, Bayliss S, Sandercock J, Burls A. Immunoprophylaxis against respiratory syncytial virus (RSV) with palivizumab in children: a systematic review and economic evaluation. Health Technol Assess [Internet]. 2008 Dec;12(36):iii, ix-x, 1-86. Available from: http://www.ncbi. nlm.nih.gov/pubmed/19049692.

55. Nuijten $M$, Lebmeier $M$, Wittenberg W. Cost effectiveness of palivizumab for RSV prevention in high-risk children in the Netherlands. J Med Econ [Internet]. 2009 Jan [cited 2013 Apr 16];12(4):291-300. Available from: http://www.ncbi.nlm.nih.gov/pubmed/19811111.

56. Hampp C, Kauf TL, Saidi AS, Winterstein AG. Cost-effectiveness of respiratory syncytial virus prophylaxis in various indications. Arch Pediatr Adolesc Med [Internet]. 2011 Jun [cited 2013 Apr 24];165(6):498-505. Available from: http://www.ncbi.nlm.nih.gov/pubmed/21300647.

57. Sanchez-Luna M, Elola FJ, Fernandez-Perez C, Bernal JL, Lopez-Pineda A. Trends in respiratory syncytial virus bronchiolitis hospitalizations in children less than 1 year: 2004-2012. Curr med res Opin [internet]. 2016;32(4):693-698. Available from: http://www.ncbi.nlm.nih.gov/pubmed/26709735.

58. OECD. Society at a Glance 2009. OECD Publishing.

59. Daymont C, Neal A, Prosnitz A, Cohen MS. Growth in children with congenital heart disease. Pediatrics [Internet]. 2013 Jan;131(1):e236-e242. Available from: http://www.ncbi.nlm.nih.gov/pubmed/23230071.

60. ElHassan NO, Sorbero MES, Hall CB, Stevens TP, Dick AW. Cost-effectiveness Analysis of Palivizumab in Premature Infants Without Chronic Lung Disease. Arch Pediatr Adolesc Med [Internet]. 2006 Oct 1;160(10):1070. Available from: http://archpedi.jamanetwork.com/article.aspx?doi=10.1001/archpedi. 160.10.1070

\section{Submit your manuscript to a SpringerOpen ${ }^{\mathcal{O}}$ journal and benefit from:}

- Convenient online submission

- Rigorous peer review

- Open access: articles freely available online

- High visibility within the field

- Retaining the copyright to your article

Submit your next manuscript at $>$ springeropen.com 